\title{
$\beta 1$ integrin- and JNK-dependent tumor growth upon hypofractionated radiation
}

\author{
Aejaz Sayeed ${ }^{1,2}$, Huimin Lu ${ }^{1,2}$, Qin Liu' ${ }^{1,3}$, David Deming II ${ }^{1,2}$, Alexander Duffy ${ }^{1,2}$, \\ Peter McCue ${ }^{4}$, Adam P. Dicker, Roger J. Davis ${ }^{6,7}$, Dmitry Gabrilovich ${ }^{1,8}$, Ulrich \\ Rodeck $^{5,9}$, Dario C. Altieri ${ }^{1,10}$ and Lucia R. Languino ${ }^{1,2,5}$ \\ ${ }^{1}$ Prostate Cancer Discovery and Development Program, Philadelphia, PA, USA \\ 2 Department of Cancer Biology, Thomas Jefferson University, Philadelphia, PA, USA \\ ${ }^{3}$ Molecular and Cellular Oncogenesis Program, The Wistar Institute, Philadelphia, PA, USA \\ ${ }^{4}$ Department of Pathology, Thomas Jefferson University, Philadelphia, PA, USA \\ ${ }^{5}$ Department of Radiation Oncology, Thomas Jefferson University, Philadelphia, PA, USA \\ ${ }^{6}$ Program in Molecular Medicine, University of Massachusetts Medical School, Worcester, MA, USA \\ ${ }^{7}$ Howard Hughes Medical Institute, University of Massachusetts Medical School, Worcester, MA, USA \\ ${ }^{8}$ Translational Tumor Immunology Program, The Wistar Institute, Philadelphia, PA, USA \\ ${ }^{9}$ Department of Dermatology and Cutaneous Biology, Thomas Jefferson University, Philadelphia, PA, USA \\ ${ }^{10}$ Tumor Microenvironment and Metastasis Program, The Wistar Institute, Philadelphia, PA, USA \\ Correspondence to: Lucia R. Languino, email: lucia.languino@jefferson.edu \\ Keywords: TRAMP mice, prostate cancer, $\beta 1$ integrins, FAK, insulin-like growth factor receptor \\ Received: November 25,2015 Accepted: June 15,2016 Published: July 11, 2016
}

\section{ABSTRACT}

Radiation therapy is an effective cancer treatment modality although tumors invariably become resistant. Using the transgenic adenocarcinoma of mouse prostate (TRAMP) model system, we report that a hypofractionated radiation schedule (10 Gy/day for 5 consecutive days) effectively blocks prostate tumor growth in wild type ( $\beta 1^{\text {wt }}$ /TRAMP) mice as well as in mice carrying a conditional ablation of $\beta 1$ integrins in the prostatic epithelium ( $\beta 1^{\mathrm{pc}-/-} /$ TRAMP). Since JNK is known to be suppressed by $\beta 1$ integrins and mediates radiation-induced apoptosis, we tested the effect of SP600125, an inhibitor of c-Jun amino-terminal kinase (JNK) in the TRAMP model system. Our results show that SP600125 negates the effect of radiation on tumor growth in $\beta 1^{\mathrm{pc} /-/}$ / TRAMP mice and leads to invasive adenocarcinoma. These effects are associated with increased focal adhesion kinase (FAK) expression and phosphorylation in prostate tumors in $\beta 1^{\mathrm{pc}-/-} /$ TRAMP mice. In marked contrast, radiation-induced tumor growth suppression, FAK expression and phosphorylation are not altered by SP600125 treatment of $\beta 1^{\text {wt }}$ /TRAMP mice. Furthermore, we have reported earlier that abrogation of insulin-like growth factor receptor (IGF-IR) in prostate cancer cells enhances the sensitivity to radiation. Here we further explore the $\beta 1 /$ IGF-IR crosstalk and report that $\beta 1$ integrins promote cell proliferation partly by enhancing the expression of IGF-IR. In conclusion, we demonstrate that $\beta 1$ integrin-mediated inhibition of JNK signaling modulates tumor growth rate upon hypofractionated radiation.

\section{INTRODUCTION}

Integrin-mediated adhesion of cancer cells to the extracellular matrix regulates the cellular response to ionizing radiation [1-3]. Our laboratory and others have shown that integrins regulate the response to radiation by modulating the activity of c-Jun NH2-terminal kinase
(JNK) [3-5], a member of the MAPK family, also known as stress-activated protein kinase [6]. Integrin regulation of JNK signaling is complex; JNK has been shown to be either activated by $\beta 1$ or $\alpha \mathrm{v}$ integrins in head and neck [4] and in nasopharyngeal cancer [5] or suppressed by $\beta 1$ integrins in prostate cancer as reported in our in vivo study [3]. 
While recent advances in radiotherapy have enabled precise targeting of tumor tissue, recurrence after radiotherapy, however, remains a concern. Many factors may lead to the failure of radiotherapy and to recurrence (Reviewed in [7]) including enhanced DNA repair, activation of tumor cell survival pathways, and inhibition of programmed cell death as well as the presence of a subpopulation of cancer stem cells that are inherently resistant to radiation (Reviewed in [8]). The conventional external beam radiation therapy used in the clinic ranges from 75.6 to 81.0 Gy of radiation divided into 1.8- to 2.0 Gy fractions, and is carried out daily between 7 and 9 weeks (Reviewed in [9]). Recently, moderate ( $<35$ fractions) and extreme ( $<5$ fractions) hypofractionated radiation therapy has been reported to yield more favorable results than conventional regimens ( $2 \mathrm{~Gy} /$ fraction), both in terms of biochemical response and toxicity [10]. However, there is no consensus in the scientific community whether hypofractionated radiation significantly reduces biochemical and/or clinical disease failure [11]. Thus, in the current study, we have investigated the effect of hypofractionated high dose radiation administered at shorter intervals (mice are irradiated with a total dose of $50 \mathrm{~Gy}$, carried out in fractionated doses of $10 \mathrm{~Gy}$, consecutively for 5 days). This simulates the approach proposed for clinical use in an effort to alleviate patient inconvenience and reduce health care costs (Reviewed in [9]). An improved understanding of the mechanisms involved in radiation-induced tumor regression may ultimately provide novel strategies of intervention in the treatment of human malignancies.

Using this hypofractionated radiation approach, we have tested the effect of a JNK inhibitor SP600125 (SP) on radiation response in wild type ( $\left.\beta 1^{\mathrm{wt}} / \mathrm{TRAMP}\right)$ mice as well as in mice carrying a conditional ablation of $\beta 1$ integrins in the prostatic epithelium ( $\left.\beta 1^{\mathrm{pc}-/ \mathrm{T}} / \mathrm{TRAMP}\right)$. $\mathrm{SP}$ is a reversible ATP-competitive inhibitor of JNK that blocks all three JNK isoforms with similar potency [12]. Its specificity is attributed to the fact that it effectively occupies the hydrophobic pocket of the ATP binding site in JNK1 and variations of crucial hydrophobic residues in other MAP kinases make JNK a selective target [13]. SP has been reported to be a selective JNK inhibitor [14] and its effectiveness against JNK in vivo has been widely reported [15-18].

In the present study, we demonstrate that the effects of JNK inhibition are contingent upon $\beta 1$ integrin expression. We studied the signaling interface between $\beta 1$ integrins and the type- 1 insulin-like growth factor receptor (IGF-IR), a trans-membrane tyrosinekinase receptor, known to play an essential role in the development and progression of cancer by regulating cell proliferation, differentiation, apoptosis and metastasis [19]. Like $\beta 1$ integrins, IGF-IR signaling has been reported to mediate resistance to radiotherapy [20, 21]. Together, these receptors play a concerted role in radio- resistance of cancer cells [3] and unraveling the nature of these interactions is expected to contribute not only to understanding the mechanisms of resistance, but also in the identification of novel therapeutic targets.

Here, we have studied $\beta 1$-mediated downstream signaling in vivo in prostate cancer resistance to hypofractionated radiation. We report that JNK inhibition compromises the beneficial effects of radiation therapy in TRAMP mice carrying conditional ablation of $\beta 1\left(\beta 1^{\mathrm{pc}-/ /} /\right.$ TRAMP), and results in a significant increase in prostate tumor growth associated with increased FAK expression and activity in these tumors.

\section{RESULTS}

\section{JNK inhibition in $\beta 1^{\mathrm{pc}-/-}$ TRAMP mice irradiated in the lower pelvis leads to prostate cancer progression}

We have previously demonstrated that conditional ablation of $\beta 1$ integrins significantly improves survival and delays prostate cancer progression in response to lower pelvis irradiation in TRAMP mice [3]. To assess the importance of JNK activation in response to radiation, 20 week-old $\beta 1^{\text {pc-- }} /$ TRAMP mice were treated with hypofractionated radiation regimen that consisted of 10 Gy fractions for 5 consecutive days (total 50 Gy). In conjunction with radiation treatment, intraperitoneal (IP) injections of SP and PPCES (PP) were administered three times/week and were continued for 9 additional weeks followed by euthanasia at 35 weeks of age. This irradiation strategy led to effective tumor suppression in $\beta 1^{\mathrm{pc}-/} / \mathrm{TRAMP}$ mice. JNK inhibition in these mice markedly compromises the effect of radiation and results in increased tumor load at the end of the treatment period. Histopathological analysis of prostate tissues from irradiated $\beta 1^{\mathrm{pc}-/} /$ TRAMP mice treated with SP consistently reveals aggressive pathological characteristics when compared to controls injected with PP which show in situ carcinoma characterized by marked papillary and cribriform epithelial proliferation with acinar expansion (Figure 1A, left panels). High magnification images of prostate tissues from SP-treated mice (Figure 1A, right panel) specifically reveal invasive carcinoma composed of anaplastic epithelioid cells growing in sheets and nests. Individual cells show marked cytologic dysplasia and areas of tissue necrosis within the expanded acini. Analysis of total tumor mass in irradiated mice injected with either PP $(n=13)$ or SP $(n=17)$ indicates that SP treatment significantly increases tumor mass in $\beta 1^{\mathrm{pc}-}$ 1- /TRAMP mice, $P<0.0001$ (Figure 1B). These results suggest that the therapeutic effect of $\beta 1$ abrogation in response to irradiation is offset by JNK inhibition. 

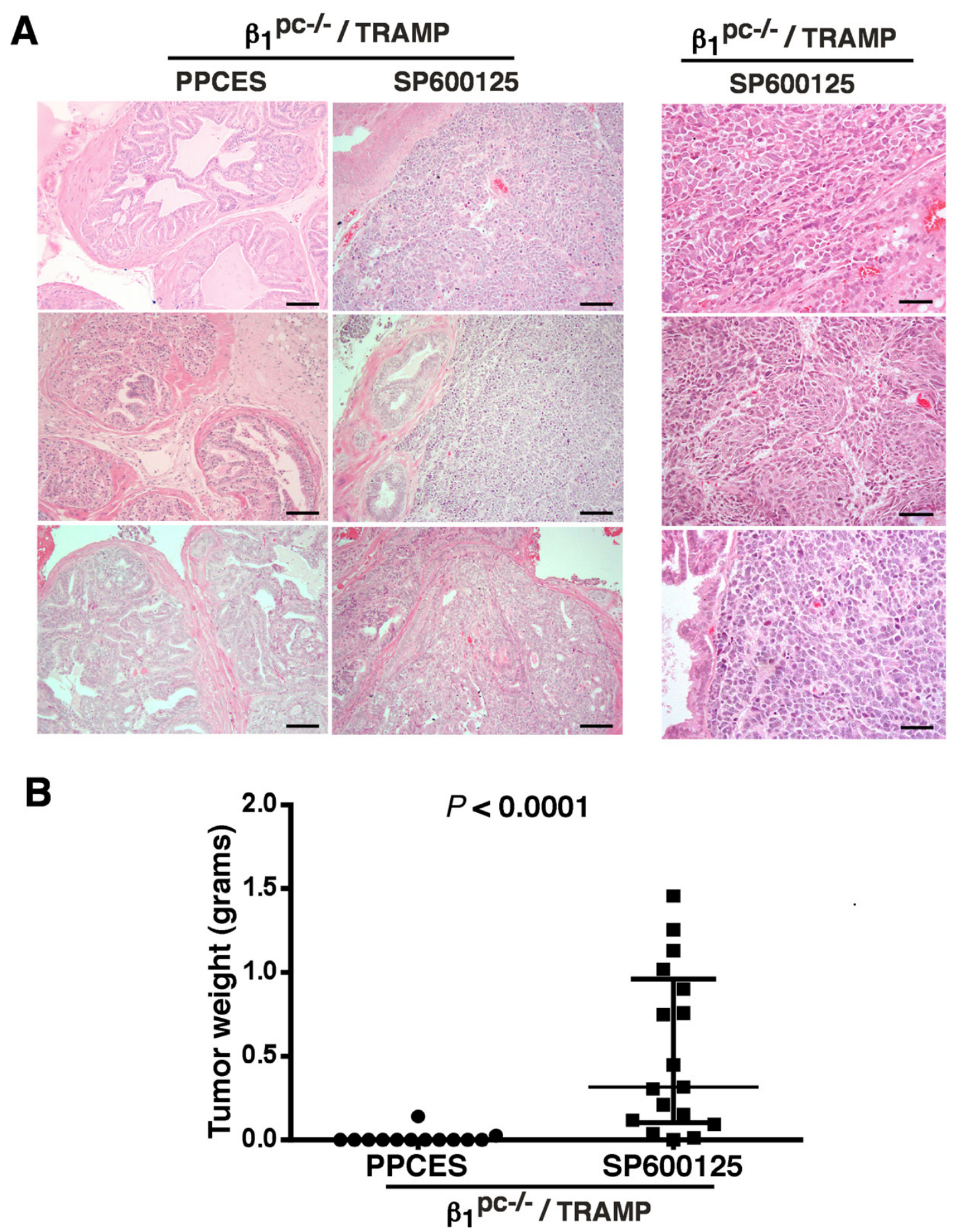

Figure 1: JNK inhibition counteracts the effect of irradiation and supports aggressive prostate growth in $\beta 1^{\mathrm{pc}-/-}$ TRAMP mice. A. Histopathological analysis after Hematoxylin and Eosin (H\&E) staining of prostate tissue from irradiated $\beta 1^{\mathrm{pc}-/ /} / \mathrm{TRAMP}$ mice. At the age of 20 weeks, mice were subjected to IP injections of vehicle PPCES or inhibitor SP600125, administered 3 times/week for 10 weeks. Two hours after the first IP injection with either PPCES or SP600125, the lower pelvises of the mice were irradiated with a hypofractionated radiation regimen that consisted of $10 \mathrm{~Gy}$ fractions (total dose $50 \mathrm{~Gy}$ ) administered for 5 consecutive days. Mice were euthanized at 35 weeks of age and prostate tissues were analyzed for tumor progression. Representative H\&E images of tissues from control or treated mice are shown (left panels). Scale bar $100 \mu \mathrm{m}$. The right panel shows representative H\&E high magnification images of prostate tumors from irradiated and SP600125-treated $\beta 1^{\mathrm{pc}-/} /$ TRAMP mice depicting aggressive histopathology. Scale bar $50 \mu \mathrm{m}$. B. The tumor mass distribution in irradiated $\beta 1^{\mathrm{pc}-/ /}$ TRAMP mice injected with PPCES vehicle or SP600125-treated is shown. Median tumor weight with interquartile range and individual data points are plotted. PPCES group $n=13$ mice, SP600125 group $n=17$ mice. A statistically significant increase in tumor mass is found in the SP600125-treated cohort as compared to the cohort injected with PPCES. $P<0.0001$ (WilcoxonMann-Whitney two-sided test). 


\section{JNK inhibition in $\beta 1^{\text {wt }}$ /TRAMP mice does not interfere with radiation-induced tumor suppression}

Since we have previously demonstrated that $\beta 1$ integrins suppress radiation-induced JNK activation [3], the JNK inhibitor was not expected to elicit any changes upon prostate irradiation in mice expressing wild type $\beta 1$ ( $\beta 1^{\mathrm{wt}} /$ TRAMP). To test whether JNK inhibition influences radiation resistance in $\beta 1^{\mathrm{wt}} /$ TRAMP prostate, we carried out irradiation and PP or SP injections in $\beta 1^{\text {wt }} /$ TRAMP mice as described above in Figure 1. Histopathological analysis of prostate tissues from irradiated $\beta 1^{\text {wt }} /$ TRAMP mice injected with either PP or SP does not show any tumor growth (Figure 2). Prostate tissues from SP-treated $\beta 1^{\mathrm{wt}}$ mice show marked papillary and cribriform epithelial hyperplasia with high-grade dysplasia (Figure 2A, right panel). In some glands, the changes are equivalent to in situ carcinoma; however, invasive carcinoma is not observed in this group. The prostatic tissues from the PP group show a spectrum of phenotypes including papillary hyperplasia with mild atypia, papillary and cribriform hyperplasia with high-grade dysplasia and combined epithelial and stromal hyperplasia with minimal cytologic atypia (Figure 2A, left panel). The differences in tumor mass between PP $(n=15)$ and SP $(n=14)$ cohorts are not significant, $P=0.41$ (Figure 2B). These data imply that JNK inhibition does not modify the radiation response in $\beta 1^{\text {wt }}$ tumors.

Collectively, these data show that JNK inhibition counteracts the effect of radiation therapy in the absence of $\beta 1$ integrins and accelerates tumor growth and progression as indicated in our schematic drawing in Figure 3A. This is consistent with our earlier findings that JNK activation is suppressed by $\beta 1$ integrins in prostate cancer cells [3] and with our new observation that exogenous JNK inhibition does not affect tumor growth in $\beta 1^{\mathrm{wt}}$ mice. To confirm SP-mediated JNK suppression in vivo, prostate tissues isolated from irradiated controls (PP cohort) and irradiated plus SP-treated $\beta 1^{\mathrm{pc}-/ /} /$ TRAMP cohort were evaluated for JNK function. Our results demonstrate that SP significantly blocks the phosphorylation of JNK in prostate tissues (Figure 3B).

\section{JNK inhibition in vivo up-regulates the expression and activation of FAK in irradiated $\beta 1^{\mathrm{pc}-/-}$ prostate tumors}

FAK is known to support tumor growth and metastasis [22], and in TRAMP mice reportedly contributes to the development of neuroendocrine carcinoma [23]. Consistent with its role in aggressive forms of the disease, FAK signaling has been associated with radiation resistance [24]. To investigate if $\beta 1$ integrins modulate FAK signaling in the presence of radiation, we evaluated FAK expression and activity profiles in our model system. Prostate tissues from irradiated and SP- treated $\beta 1^{\mathrm{pc}-/ /} /$ TRAMP mice were analyzed for the expression and phosphorylation of FAK. Our results demonstrate that JNK inhibition by SP selectively leads to the up-regulation of FAK expression and phosphorylation (Figure 4A). No changes in AKT phosphorylation, however, are observed in these tissues (Figure 4B). Consistent with FAK phosphorylation, we also observe induction of tyrosine kinase Src expression and phosphorylation upon JNK inhibition in tissues from $\beta 1^{\mathrm{pc}-/ /} /$ TRAMP mice (data not shown). In order to study the histological localization of FAK, prostate tissues from SP-treated $\beta 1^{\mathrm{pc}-/} /$ TRAMP mice were analyzed for

A

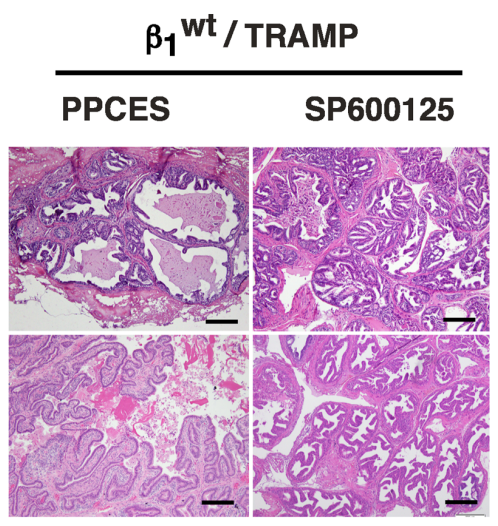

B

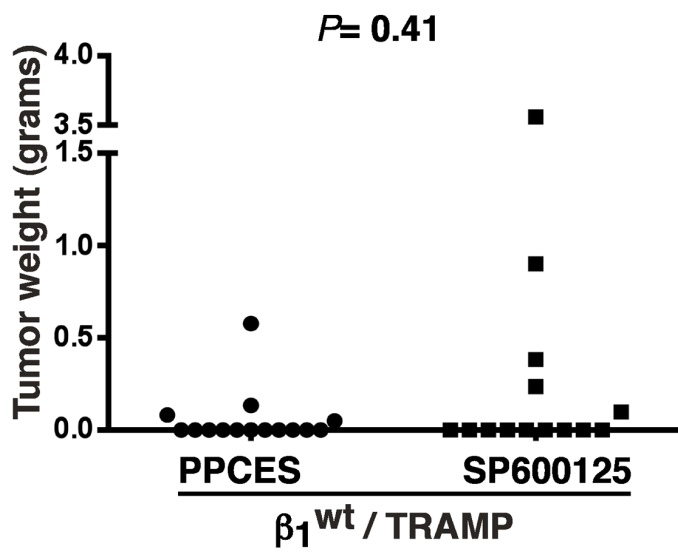

Figure 2: JNK inhibition in $\beta 1^{\text {wt }} /$ TRAMP mice does not offset the effect of radiation on tumor growth. A. Histopathological analysis of irradiated tumors from $\beta 1^{\text {wt }} /$ TRAMP mice treated as described in Figure 1. Representative $\mathrm{H} \& \mathrm{E}$ images of tissues from control or treated mice are shown. Scale bar $100 \mu \mathrm{m}$. B. The tumor mass distribution in lower pelvis-irradiated $\beta 1^{\mathrm{wt}} /$ TRAMP mice injected with PPCES or SP600125 is shown. Median tumor weight and individual data points are plotted. PPCES group $n=15$ mice, SP600125 group $n$ $=14$ mice. No statistically significant differences in tumor mass are found between SP and vehicle treated $\beta 1^{\mathrm{wt}} /$ TRAMP cohorts. $P=0.4094$ (Wilcoxon-Mann-Whitney two-sided test). 
Table 1: Expression profile and localization of FAK in prostate tissues from irradiated and/or SP-treated $\beta 1^{\mathrm{p}-/-{ }^{-}}$/ TRAMP mice.

\begin{tabular}{|c|c|c|c|c|c|}
\hline \multirow{2}{*}{$\begin{array}{l}\text { Mouse } \\
\text { Number }\end{array}$} & \multirow{2}{*}{ JNK inhibitor } & \multirow{2}{*}{ Histopathology } & \multicolumn{2}{|c|}{ FAK intensity } & \multirow{2}{*}{$\begin{array}{c}\text { FAK Positive } \\
\text { Fields } \\
\text { [Percentage] }\end{array}$} \\
\hline & & & Nuclear & Cytoplasmic & \\
\hline 1 & + & Invasive carcinoma & 3 & - & $100 \%$ \\
\hline 2 & + & $\begin{array}{l}\text { Aggressive high grade tumor, neuroendocrine } \\
\text { phenotype }\end{array}$ & 3 & - & $100 \%$ \\
\hline 3 & + & High grade tumor, carcinoma in situ & 3 & - & $100 \%$ \\
\hline 4 & + & High grade tumor & 3 & - & $100 \%$ \\
\hline 5 & + & Carcinoma in situ and high grade PIN & 3 & - & $100 \%$ \\
\hline 6 & + & High grade tumor & 3 & 1 & $100 \%$ \\
\hline 7 & + & High grade tumor & 3 & 3 & $100 \%$ \\
\hline 8 & + & $\begin{array}{l}\text { Aggressive high grade tumor, high grade PIN, } \\
\text { invasive carcinoma, unusual papillary cells }\end{array}$ & $2-3$ & $2-3$ & $90 \%$ \\
\hline 9 & + & High grade aggressive tumor & 3 & 3 & $80 \%$ \\
\hline 10 & + & High grade tumor & $2-3$ & $2-3$ & $80 \%$ \\
\hline 11 & _- & Carcinoma in situ, benign, PIN & $1-2$ & $1-2$ & $100 \%$ \\
\hline 12 & - & Well contained high grade PIN & $1-2$ & $1-2$ & $90 \%$ \\
\hline 13 & - & Carcinoma in situ, high grade PIN & $1-2$ & $1-2$ & $80 \%$ \\
\hline 14 & _- & Benign, atypical to well defined PIN & 1 & 1 & $70 \%$ \\
\hline 15 & _- & PIN, tumor plus dysplasia & 1 & 1 & $60 \%$ \\
\hline 16 & - & No tumor, abscess & 1 & - & $50 \%$ \\
\hline 17 & - & $\begin{array}{l}\text { Carcinoma in situ, locally invasive, high grade } \\
\text { tumor }\end{array}$ & 2 & 1 & $40 \%$ \\
\hline 18 & - & $\begin{array}{l}\text { Focal high grade PIN, carcinoma in situ, } \\
\text { papillary hyperplasia }\end{array}$ & $1-2$ & $1-2$ & $40 \%$ \\
\hline 19 & - & Normal glandular morphology & 1 & 1 & $30 \%$ \\
\hline 20 & _ & Typical hyperplasia, no tumor & 1 & 1 & $20 \%$ \\
\hline
\end{tabular}

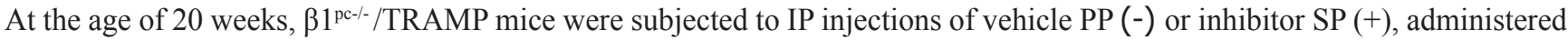
3 times/week for 10 weeks. Two hours after the first IP injection with either PP or SP, the lower pelvises of the mice were irradiated with a hypofractionated radiation regimen that consisted of $10 \mathrm{~Gy}$ fractions (total dose $50 \mathrm{~Gy}$ ) administered for 5 consecutive days. Mice were euthanized at 35 weeks of age and paraffin-embedded formalin-fixed prostate tissues were analyzed for FAK expression patterns. Histological features of 10 PP and 10 SP tissues are shown. "Percentage positive areas" at $x 40$ optical magnification represents the number of cytoplasmic and/or nuclear FAK-positive regions over ten independent areas in each specimen analyzed. An optical region of a sample that showed more than $50 \%$ of cells with positive FAK staining was scored as FAK positive; FAK expression was scored using a 1-3 arbitrary scale in the FAK intensity column. -, indicates undetectable levels. 
FAK expression patterns by immunohistochemistry. Ten specimens in the PP and SP cohorts were studied for FAK intensity and scored. Our data indicate that SP-treated specimens show relatively higher FAK intensity and enhanced nuclear localization in comparison to the PPcontrol cohort (Table 1 and Figure 5). These data highlight the role of $\beta 1$ and JNK signaling in FAK regulation and strongly suggest a role for FAK in $\beta 1$-dependent radiation resistance of prostate cancer.

\section{JNK inhibition in vivo fails to enhance FAK/AKT signaling upon irradiation in $\beta 1^{\mathrm{wt}} / \mathrm{TRAMP}$ mice}

Since JNK inhibition leads to the induction of FAK signaling in $\beta 1^{\mathrm{pc}-/ \mathrm{T}} / \mathrm{TRAMP}$ prostate tumors, we assessed the FAK profile in $\beta 1^{\mathrm{wt}} /$ TRAMP prostate tissues. $\beta 1$ integrins are known to regulate FAK signaling [4] and we have previously demonstrated that $\beta 1$ integrins suppress radiation-induced JNK signaling in prostate cancer [3]. Consistent with a dominant role of $\beta 1$ integrins in

\section{A}

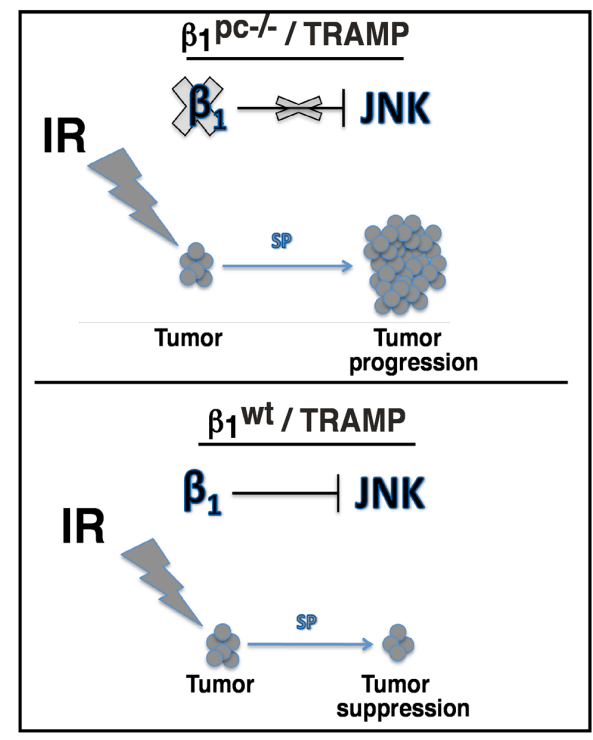

B

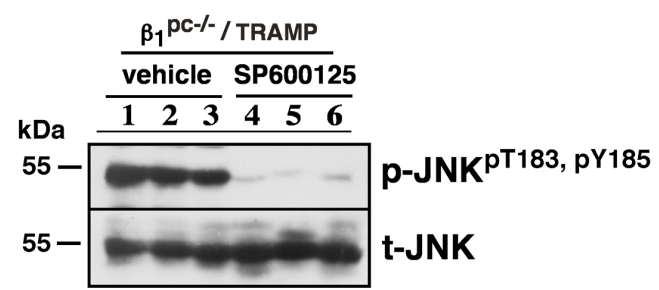

Figure 3: JNK signaling is crucial for radiationdependent tumor suppression in the absence of $\beta 1$ integrins. A. Schematic representation showing that the effect of radiation is offset by JNK inhibition in $\beta 1^{\mathrm{pc}-/} / \mathrm{TRAMP}$ mice (upper panel). In contrast, the effect of radiation persists in SP600125-treated $\beta 1^{\mathrm{wt}} /$ TRAMP mice (lower panel). B. Immunoblot analysis shows the total and $\mathrm{JNK}^{\mathrm{pT} 183, \mathrm{pY} 185}$ levels in irradiated prostate tissues of $\beta 1^{\mathrm{pc}-/} /$ TRAMP mice treated as in Figure 1. suppressing JNK1 activation in $\beta 1^{\mathrm{wt}} / \mathrm{TRAMP}$ mice, JNK inhibition in $\beta 1^{\text {wt }} /$ TRAMP prostate tissues does not enhance FAK signaling (Figure 6A); we also observe that JNK inhibition in $\beta 1^{\text {wt }}$ TRAMP prostate tissues does not enhance AKT signaling. Conversely, our results indicate that JNK-inhibition dependent FAK up-regulation in prostate tumors selectively occurs in the absence of $\beta 1$ integrins. We also investigated the expression of a neuroendocrine marker, chromogranin, in $\beta 1^{\mathrm{pc}-/}$ and $\beta 1^{\mathrm{wt}}$ /TRAMP prostate tissues. Chromogranin expression is detected in both $\beta 1^{\mathrm{pc}-/-}$ and $\beta 1^{\mathrm{wt}}$ tissues regardless of JNK inhibition implying that $\beta 1$, JNK or FAK signaling does not influence chromogranin expression in our model (Figure 6B).

\section{$\beta 1$ integrins regulate IGF-IR expression to enhance prostate cancer cell proliferation}

We have previously reported that $\beta 1$ integrin expression is regulated by IGF-IR, a receptor known
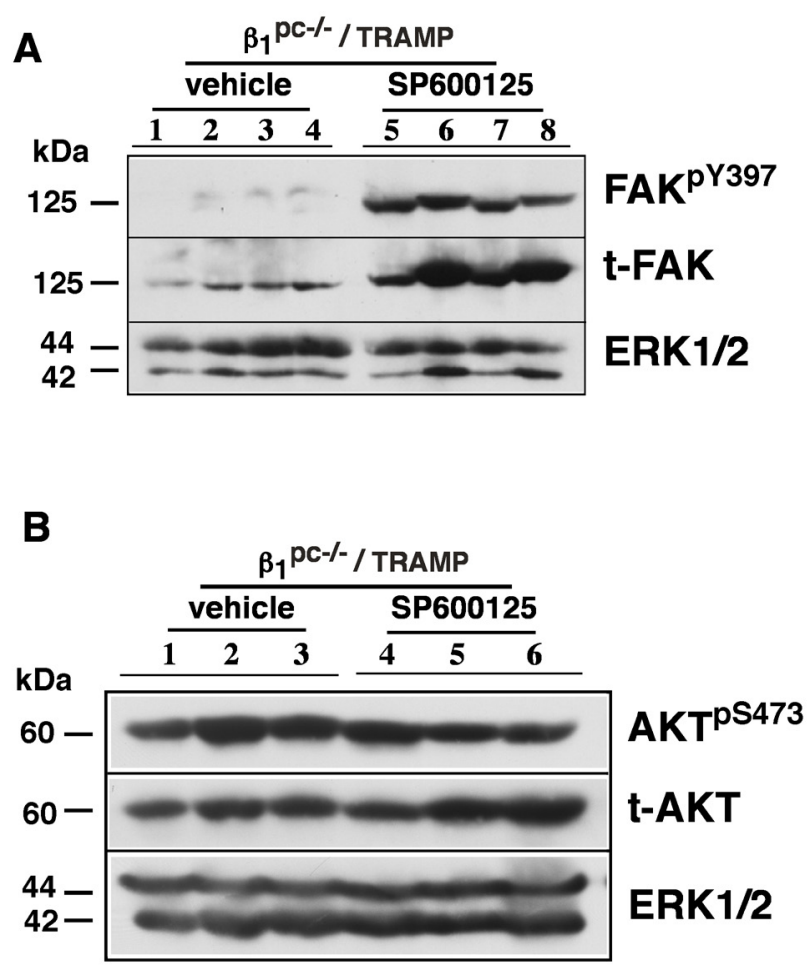

Figure 4: Tumor growth upon irradiation and JNK inhibition in $\beta 1^{\mathrm{pc}-/} /$ TRAMP mice is associated with enhanced FAK signaling. A. Induction of FAK expression and phosphorylation in prostate tumors from $\beta 1^{\mathrm{pc}-/ \mathrm{T}} / \mathrm{TRAMP}$ mice. Immunoblot analysis of prostate tissues from $\beta 1^{\mathrm{pc}-/} /$ TRAMP mice treated as described in Figure 1. Prostate tissues were snap frozen. Tissues were homogenized and lysates analyzed by SDS-PAGE using Abs against $\mathrm{FAK}^{\mathrm{pY} 397}$ and total FAK. ERK1/2 was used as a loading control. B. Immunoblotting analysis of prostate tissues from $\beta 1^{\mathrm{pc}-/} / \mathrm{TRAMP}$ mice showing $\mathrm{AKT}^{\mathrm{pS} 473}$ and total AKT in prostate tissues as described above in Figure 4A. ERK1/2 was used as a loading control. 


\section{FAK \\ $\beta_{1} \overline{\text { pc-I- / TRAMP }}$}

PPCES
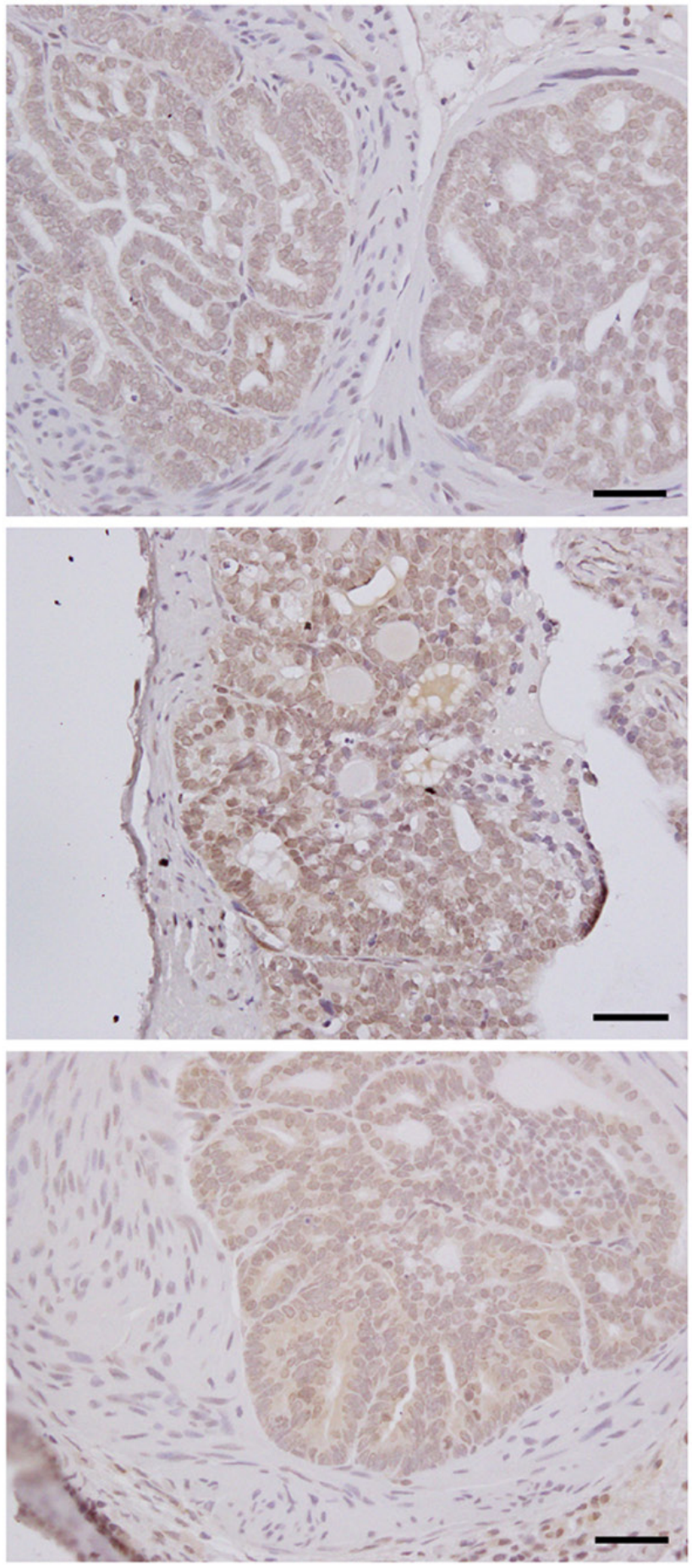

SP600125
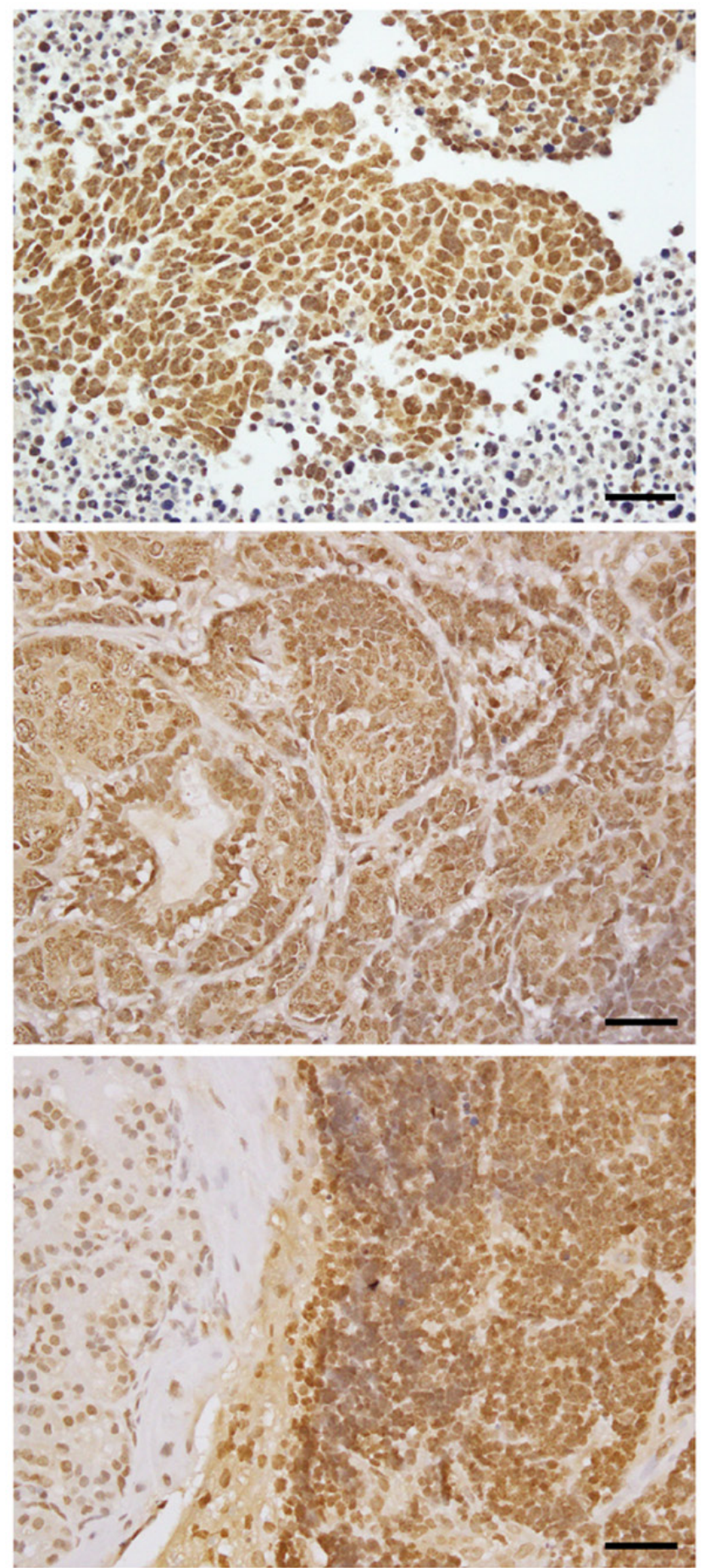

Figure 5: Irradiation coupled with JNK inhibition in $\beta 1^{\mathrm{pc}--/} /$ TRAMP mice leads to increased levels of nuclear FAK in tumor cells. FAK expression profile in paraffin-embedded tissue sections from irradiated and SP600125-treated $\beta 1^{\mathrm{p}-/ /} /$ TRAMP mice are shown. Ten specimens in control PPCES and SP600125-treated cohorts were analyzed. Representative expression profiles are shown here. Scale bar $50 \mu \mathrm{m}$. 
to promote resistance to radiation, and that abrogation of IGF-IR in prostate cancer cells leads to the loss of $\beta 1$ integrins by proteasomal degradation [25]. Here we investigate whether $\beta 1$ integrins affect IGF-IR expression. LNCaP cells were transiently transfected with $\beta 1$-pcDNA together with control or IGF-IR siRNA to evaluate the expression of IGF-IR. Our results demonstrate that overexpression of $\beta 1$ leads to the up-regulation of IGF-IR (Figure 7A). However, IGF-IR down-regulation eliminates

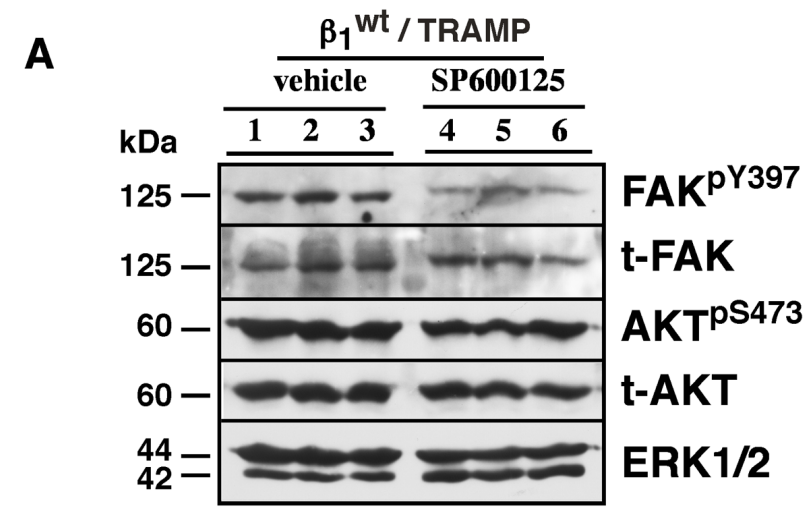

B

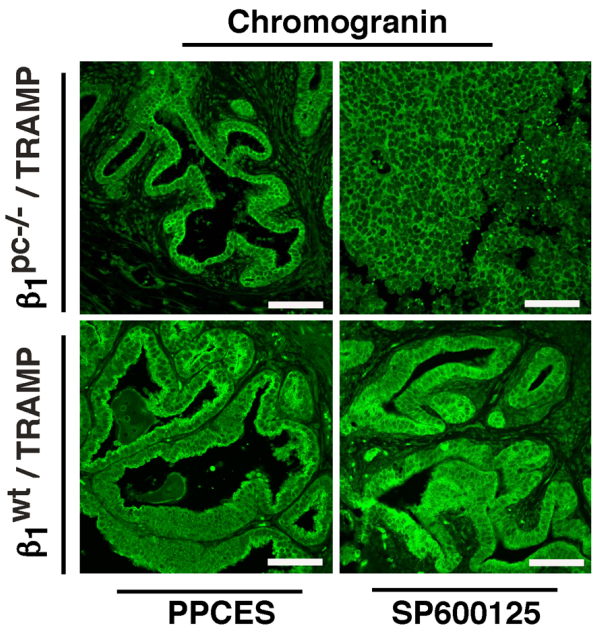

Figure 6: FAK/AKT signaling is not altered upon lower pelvis irradiation and JNK inhibition in $\beta 1^{\text {wt }} /$ TRAMP mice. A. Immunoblot analysis of prostate tissues from $\beta 1^{\mathrm{wt}} /$ TRAMP mice treated as described in Figure 1. Frozen tissues were homogenized and lysates analyzed by SDS-PAGE using antibodies against total FAK, FAK ${ }^{\mathrm{pY} 397}$, total AKT and $\mathrm{AKT}^{\mathrm{p} 5473}$. ERK1/2 was used as a loading control. B. Neuroendocrine differentiation in response to irradiation and JNK inhibition in either $\beta 1^{\mathrm{pc}-/} /$ TRAMP or $\beta 1^{\mathrm{wt}} /$ TRAMP prostate tissues. Number of mice analyzed: PPCES group $\beta 1^{\mathrm{pc}-/} / \mathrm{TRAMP}, n=5$; SP600125 group $\beta 1^{\mathrm{pc}-/} /$ TRAMP, $n=3$; PPCES group $\beta 1^{\mathrm{wt}} /$ TRAMP, $n=3$ and SP600125 group $\beta 1^{\text {wt }} /$ TRAMP, $n=3$. Representative images reflecting the expression profile of chromogranin in $\beta 1^{\mathrm{pc}-/}$ or $\beta 1^{\mathrm{wt}}$ TRAMP mice. Prostate tissues from $\beta 1^{\mathrm{pc}-/}$ or $\beta 1^{\mathrm{wt}} /$ TRAMP mice treated as in Figure 1A above were fixed; sections were stained with a chromogranin $\mathrm{Ab}$ and processed for immunofluorescence. Counterstaining was done with DAPI not shown and expression profiles were studied by confocal microscopy. Scale bar $100 \mu \mathrm{m}$. exogenous increase in $\beta 1$ protein levels suggesting that the stability of $\beta 1$ is dependent on IGF-IR, reinforcing our previous observation that in the absence of IGF-IR, $\beta 1$ is rapidly metabolized through proteasomal degradation. Both IGF-IR and $\beta 1$ receptors seem to co-exist in a functional complex and stabilize each other's expression in cancer cells. As shown in Figure 7B, exogenous induction of $\beta 1$ significantly promotes cancer cell proliferation. Concurrent IGF-IR down-regulation reduces $\beta 1$ levels

A

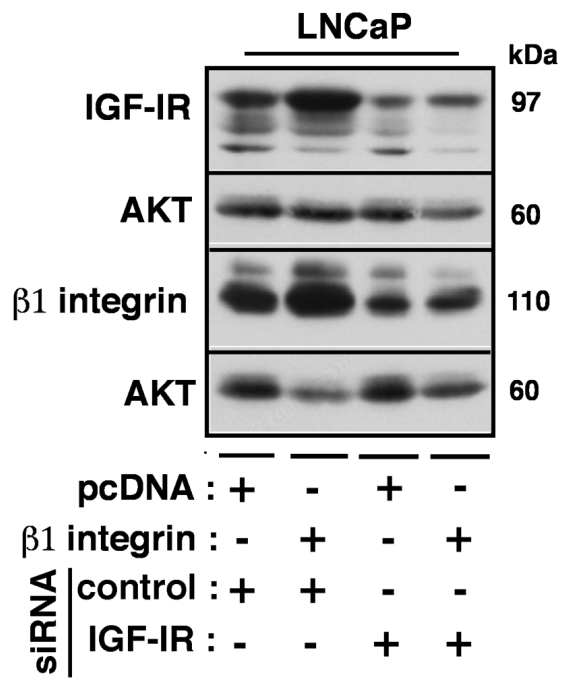

B

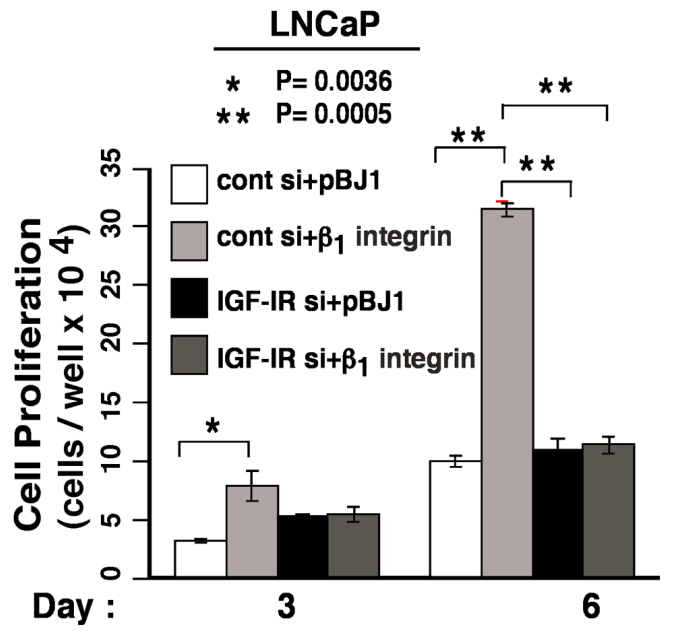

Figure 7: $\beta 1$ integrins promote cancer cell proliferation by regulating the expression of IGF-IR. A. Exogenous $\beta 1$ induction leads to the up-regulation of IGF-IR expression. LNCaP cells were transiently transfected with either pBJ1 or $\beta 1$-pBJ1 constructs, together with control or IGF-IR siRNA; 48 hours later, cell lysates were analyzed by immunoblotting analysis for expression of the $\beta 1$ integrin subunit and IGF-IR. AKT was used as a loading control. B. Exogenous $\beta 1$ induction enhances cancer cell proliferation, which is blocked by IGFIR knockdown. LNCaP cells transfected as in Figure 7A were replated in equal numbers in culture dishes and allowed to grow for either 3 or 6 days followed by live cell counting. Each assay was performed in triplicate and asterisk signs represent statistical significance. 
and thus significantly stalls cell proliferation suggesting that $\beta 1$ functions are intrinsically dependent on IGFIR expression in prostate cancer cells. Thus, it could be speculated that both IGF-IR and $\beta 1$ receptors concertedly modulate JNK signaling in response to radiation.

\section{DISCUSSION}

Using a novel hypofractionated radiation schedule that effectively blocks prostate tumor growth in TRAMP mice, we show that blocking JNK signaling using a JNK1, 2 and 3 inhibitor (SP600125), counteracts the effects of therapeutic radiation and leads to tumor growth and progression, in a $\beta 1$ integrin-dependent manner.

Here we have tested a hypofractionated radiation scheme where a 50 Gy total dose of radiation was administered in 10 Gy fractions for 5 consecutive days, to approximate the hypofractionated approach in patients. This radiation schedule effectively suppresses tumor growth in $\beta 1^{\mathrm{wt}}$ mice and also in $\beta 1^{\mathrm{pc}-/-}$ mice which carry a conditional ablation of $\beta 1$ integrins in the prostatic epithelium. However, inhibition of JNK phosphorylation negates the therapeutic effect of hypofractionated radiation in $\beta 1^{\mathrm{pc}-/-} /$ TRAMP but not $\beta 1^{\mathrm{wt}} /$ TRAMP mice. This is consistent with the notion that $\beta 1$ integrin-dependent signaling determines the functional role of JNK as it relates to radiation response of the prostate epithelium.

Our study delineates a JNK-mediated signaling pathway, which modulates tumor growth upon irradiation in a differential manner dependent on $\beta 1$ expression. It is widely accepted that ionizing radiation activates multiple signal transduction pathways, including the JNK/SAPK cascade, which transduce death signals from the cell membrane to the nucleus. Since $\beta 1$ integrins suppress JNK activation induced by radiation [3], SP treatment, as expected, did not affect radiation-induced tumor suppression in $\beta 1^{\mathrm{wt}}$ mice. Our results are in contrast with a previous report where inhibition of $\beta 1$ integrins in head and neck carcinoma cells was reported to be associated with down-regulation of JNK signaling leading to radiosensitization [4]. However, there is substantial evidence demonstrating a pro-apoptotic role of JNK in response to radiation [26-29], which is consistent with our results. Although integrin interaction with the cytoskeleton is likely to mediate JNK activation, the association of $\beta 1$ with the cytoskeletal protein, filamin A [30] is not likely to explain our results since filamin A binds stress signaling kinases MKK4 and MKK7 and is known to enhance JNK activation [31] whereas $\beta 1$ integrins suppress radiationdependent JNK signaling.

A unique feature of irradiated and SP-treated $\beta 1^{\mathrm{pc}-/}$ tumors is the up-regulation of FAK expression and autophosphorylation which is not observed in $\beta 1^{\mathrm{pc}-/-}$ tissues from mice with functional JNK signaling or in $\beta 1^{\text {wt }}$ tissues where JNK is inhibited. FAK auto-phosphorylation at tyrosine 397 (FAK $^{\mathrm{pY} 397}$ ) exposes a site for Src, which leads to Src-dependent phosphorylation of FAK at tyrosines $576\left(\mathrm{FAK}^{\mathrm{pY} 576}\right)$ and $577\left(\mathrm{FAK}^{\mathrm{pY} 577}\right)$ leading to maximal adhesion-induced FAK activation [32]. FAK expression has been reported to be enhanced in all stages of prostate tumorigenesis, to regulate anti-tumor immunity and integrin-dependent radioresistance [33-36]. Recently, nuclear FAK was reported to regulate immunomodulatory functions and inhibit anti-tumor immunity in cancerous squamous epithelial cells by regulating chemokine/ cytokine and ligand receptor networks [36], which is consistent with our results. FAK activity has further been implicated in DNA damage induced NF- $k$ B activation and production of cytokines from endothelial cells leading to chemoresistance [37]. Similarly, $\beta 1$ integrindependent FAK signaling was reported to elicit faster cell attachment rates and reduced adhesion strength in taxolresistant ovarian cancer cells [38]. The authors report that adhesion strength is dependent on FAK. Besides, faster attachment rates and reduced adhesion strength, in these cells, correlate with increased $\beta 1$ integrin expression and decreased focal adhesion formation, respectively. In addition, drug-tolerant microenvironments are known to be correlated with high $\beta 1$ integrin/FAK signaling in melanoma cells [39]. Our data indicating high FAK expression and phosphorylation associated with tumor progression upon radiation, are consistent with these studies and collectively highlight a central role of FAK in therapeutic resistance.

Activation of AKT has been reported earlier as an important predictor of the probability of PSA failure and a marker of clinically aggressive prostate cancer [40]. There is a significant interest in developing effective strategies to target this pathway [41]. In our studies, however, AKT activation in irradiated prostate tissues does not change upon JNK inhibition ruling out a significant functional contribution of JNK-dependent AKT activation in prostate cancer development in SP-treated $\beta 1^{\mathrm{pc}-/ \mathrm{-}}$ TRAMP mice. Finally, although sustained FAK expression and activity have been reported to be essential for androgenindependent formation of neuroendocrine carcinoma [23], we observe significant chromogranin expression in TRAMP tissues that is not altered by either JNK inhibition or $\beta 1$ abrogation.

Furthermore, our earlier report showed that abrogation of IGF-IR in prostate cancer cells enhances the sensitivity to radiation in a clonogenic assay [25]. Here we show that $\beta 1$ integrins promote cell proliferation partly by enhancing the expression of IGF-IR underscoring the importance of $\beta 1 /$ IGF-IR functional synergy. Using in vitro model systems of prostate cancer we have demonstrated a functional crosstalk between $\beta 1$ integrins and IGF-IR and shown that these two vital receptors regulate each others' expression [25]. In the present report, we further demonstrate that exogenous $\beta 1$ integrins 
up-regulate IGF-IR expression leading to enhanced cell proliferation. This is consistent with our previous findings where abrogation of IGF-IR led to reduced $\beta 1$ levels via proteasomal degradation and enhanced radiation sensitivity of prostate cancer cells $[3,25]$. The identification of aberrant signaling pathways broaden the current concept of radiation sensitivity in exploring multitargeting molecular agents and aid in the development of novel therapeutic approaches.

In summary, we demonstrate that inhibition of JNK reactivates the growth of irradiated tumors, in a differential manner that depends on $\beta 1$ integrins, and promotes FAK expression and activity. These findings have implications for the future design of combination therapies encompassing ionizing radiation and signal transduction modifiers.

\section{MATERIALS AND METHODS}

\section{Reagents and antibodies}

SP600125 (SP) was purchased from LC Laboratories. Murine monoclonal (m) antibodies (Abs) against the following antigens were used: human $\beta 1$, TS2/16 (ATCC); $\beta 1$, clone-18; JNK1/JNK2 (BD Pharmingen); c-Src (Cell Signaling). Rabbit polyclonal Abs against the following antigens were used: IGF-IR (IGF-IR- $\beta$ sc713); AKT; FAK; ERK1/2 (Santa Cruz); chromogranin (Invitrogen); $\mathrm{FAK}^{\mathrm{pY} 397}, \mathrm{Src}^{\mathrm{pY} 416}, \mathrm{JNK}^{\mathrm{pT} 183 \text {, }}$ ${ }^{\mathrm{pY} 185}, \mathrm{AKT}^{\mathrm{p} 443}$ and AKT (Cell Signaling). Non-immune rabbit IgG was purchased from Pierce. Alexa Fluor 488 goat anti-rabbit IgG was purchased from Invitrogen.

\section{Cell lines}

LNCaP prostate cancer cells were purchased from ATCC and authenticated by the supplier. Cells were grown at $37^{\circ} \mathrm{C}$ and $5 \% \mathrm{CO} 2$ in RPMI-1640 supplemented with $5 \% \mathrm{FBS}$ and $1 \%$, each of sodium pyruvate, HEPES and non-essential amino acids.

\section{Mice}

TRAMP mice carrying conditional ablation of $\beta 1$ $\left(\beta 1^{\mathrm{pc}-/-} /\right.$ TRAMP) and those expressing wild type $\beta 1\left(\beta 1^{\mathrm{wt}}\right.$ /TRAMP) were generated as described earlier [3]. Care of animals was in compliance with standards established by the office of laboratory animal welfare, Department of Health and Human Services at NIH. Experimental protocols were approved by the Institutional Animal Care and Use Committee, Thomas Jefferson University.

\section{SP injection and hypofractionated irradiation}

SP was suspended in PP mixture comprising of $30 \%$ PEG-400, 20\% polypropylene glycol, 15\% cremophor, $5 \%$ ethanol and $30 \%$ saline [12]. At the age of 20 weeks, $\beta 1^{\mathrm{pc}-/-} /$ TRAMP and $\beta 1^{\mathrm{wt}} /$ TRAMP mice were subjected to IP injections of vehicle PP $(150 \mu \mathrm{l})$ or inhibitor SP $(30 \mathrm{mg} /$ $\mathrm{kg}$ ), administered 3 times / week for 10 weeks. Two hours after the first IP injection with either PP or SP, the lower pelvis of the mice was irradiated with 10 Gy radiation as a part of hypofractionated radiation regimen that consisted of 10 Gy fractions (total dose $50 \mathrm{~Gy}$ ) administered for 5 consecutive days. Animals were anesthetized with Ketamine-Xylazine-Acepromazine mixture $\quad(0.125$ $\mathrm{ml} / 100 \mathrm{~g}$ of body weight),(Ketamine, $80 \mathrm{mg} / \mathrm{ml}$; Xylazine $5 \mathrm{mg} / \mathrm{ml}$; Acepromazine, $1.6 \mathrm{mg} / \mathrm{ml}$ ) providing 25-30 minutes sedation, prior to being placed in malleable lead shielding. The shield ensures that upper body including upper gastrointestinal tract is protected. Lower pelvises of mice were irradiated using a PanTak $310 \mathrm{keV}$ X-ray machine at $0.25 \mathrm{~mm} \mathrm{Cu}$ plus $1 \mathrm{~mm} \mathrm{Al}$ added filtration, at $125 \mathrm{cGy} / \mathrm{min}$. Mice were euthanized at the age of 35 weeks for studying tumor progression. Prostate isolation was performed using a dissection stereomicroscope SZX10 (Olympus). Prostate tissues were weighed and fixed for histopathologic analysis. A small amount of tissue was frozen for immunoblotting analysis. Lungs, liver and lymph nodes were fixed for studying metastasis.

\section{Immunohistochemistry (IHC)}

IHC analysis was carried out as reported earlier [3]. Lungs, liver and lymph nodes from mice were processed in the same manner and stained with H\&E for studying metastasis. Histological analysis of prostate and metastases was performed by Dr. Peter McCue. Total FAK levels were analyzed in paraffin-embedded formalin-fixed tumor sections of $\beta 1^{\mathrm{pc}-\mathrm{-} / \mathrm{TR} A M P}$ mice by IHC as reported earlier for other molecules [42], with the exception of using biotin-streptavidin-amplified peroxidase immunodetection system with DAB kit (Invitrogen).

\section{Immunofluorescence and confocal microscopy}

Immunofluorescence was carried out as described earlier [43]. Staining with an Ab to chromogranin was performed by incubation of tissue samples with primary Abs (1:100) for 1 hour at RT, followed by incubation with Alexa Fluor 488 goat rabbit IgG (1:250) for 20 minutes at RT. 


\section{Transient transfection}

Transfection of cells with siRNA oligonucleotides (Thermo Scientific) was performed as previously described [44]. To -regulate IGF-IR, the sequences of sense strands of duplex siRNAs used are as follows: IGF-IR-siRNA: 5'-CGACUAUCAGCAGCUGAAGUUdTdT-3'; control IGF-IR-siRNA: 5'-GAAGUCGACGACUAUCAGCU UdTdT-3' [25].

\section{Cell proliferation assay}

LNCaP cells were transfected with either empty vector $\mathrm{pBJ} 1$ or recombinant $\beta 1-\mathrm{pBJ} 1$ plasmid together with either control siRNA or IGF-IR siRNA [25]. Cells were trypsinized 24 hours after transfection and plated in triplicate sets in fresh growth medium at $1.5 \times 10^{4} \mathrm{cells} / \mathrm{well}$ in 6-well plates. Cells for growth assay were harvested at day 3 and day 6 after plating. Cells were trypsinized and pellets resuspended in $500 \mu 1$ of PBS followed by livecell counting using hemocytometer. In parallel, cells were plated in $10 \mathrm{~cm}$ dishes to evaluate expression changes by immunoblotting.

\section{Immunoblotting (IB)}

IB was performed on tumor and cell lysates as reported earlier [25, 43].

\section{Statistical analysis}

Wilcoxon-Mann-Whitney test was used to compare the median tumor weight. Interquartile range and individual data points were plotted to compare the tumor mass between vehicle and SP-treated $\beta 1^{\mathrm{pc}-/} /$ TRAMP and $\beta 1^{\text {wt }} /$ TRAMP groups. Statistical analysis for proliferation assay was performed using two-tailed t-test.

\section{CONFLICTS OF INTEREST}

The authors declare no conflict of interest.

\section{GRANT SUPPORT}

This study was supported by NIH R01 CA89720 and CA-109874 (to LRL), P01 CA-140043 (to LRL and DCA); by a Thomas Jefferson University Dean's Transformational Science Award; by a Prostate Cancer Foundation Challenge Award and by American Cancer Society (ACS)-IRG-08-060-04 (to AS). This project is also funded, in part, under a Commonwealth University Research Enhancement Program grant with the Pennsylvania Department of Health (H.R.); the
Department specifically disclaims responsibility for any analyses, interpretations or conclusions; the Sidney Kimmel Cancer Center Bioimaging and Histology Core Facilities were supported by the NCI, National Institutes of Health, under Award P30CA056036.

\section{REFERENCES}

1. Sandfort V, Koch U and Cordes N. Cell adhesion-mediated radioresistance revisited. Int J Radiat Biol. 2007; 83:727732.

2. Park CC, Zhang HJ, Yao ES, Park CJ and Bissell MJ. $\beta 1$ integrin inhibition dramatically enhances radiotherapy efficacy in human breast cancer xenografts. Cancer Res. 2008; 68:4398-4405.

3. Goel HL, Sayeed A, Breen M, Zarif MJ, Garlick DS, Leav I, Davis RJ, Fitzgerald TJ, Morrione A, Hsieh CC, Liu Q, Dicker AP, Altieri DC and Languino LR. $\beta 1$ integrins mediate resistance to ionizing radiation in vivo by inhibiting c-Jun amino terminal kinase 1. J Cell Physiol. 2013; 228:1601-1609.

4. Eke I, Deuse Y, Hehlgans S, Gurtner K, Krause M, Baumann M, Shevchenko A, Sandfort V and Cordes N. $\beta 1$ / $\mathrm{FAK} /$ cortactin signaling is essential for human head and neck cancer resistance to radiotherapy. J Clin Invest. 2012; 122:1529-1540.

5. Ou J, Luan W, Deng J, Sa R and Liang H. $\alpha \mathrm{V}$ integrin induces multicellular radioresistance in human nasopharyngeal carcinoma via activating SAPK/JNK pathway. PLoS One. 2012; 7(6):e38737.

6. Davis RJ. Signal transduction by the JNK group of MAP kinases. Cell. 2000; 103:239-252.

7. Begg AC, Stewart FA and Vens C. Strategies to improve radiotherapy with targeted drugs. Nat Rev Cancer. 2011; 11:239-253.

8. Al-Dimassi S, Abou-Antoun T and El-Sibai M. Cancer cell resistance mechanisms: a mini review. Clin Transl Oncol. 2014; 16:511-516.

9. Aneja S, Pratiwadi RR and Yu JB. Hypofractionated radiation therapy for prostate cancer: risks and potential benefits in a fiscally conservative health care system. Oncology (Williston Park). 2012; 26:512-518.

10. Clemente S, Nigro R, Oliviero C, Marchioni C, Esposito M, Giglioli FR, Mancosu P, Marino C, Russo S, Stasi M, Strigari L, Veronese I and Landoni V. Role of the technical aspects of hypofractionated radiation therapy treatment of prostate cancer: a review. Int J Radiat Oncol Biol Phys. 2015; 91:182-195.

11. Pollack A, Walker G, Horwitz EM, Price R, Feigenberg S, Konski AA, Stoyanova R, Movsas B, Greenberg RE, Uzzo RG, Ma C and Buyyounouski MK. Randomized trial of hypofractionated external-beam radiotherapy for prostate cancer. J Clin Oncol. 2013; 31:3860-3868.

12. Bennett BL, Sasaki DT, Murray BW, O’Leary EC, Sakata 
ST, Xu W, Leisten JC, Motiwala A, Pierce S, Satoh Y, Bhagwat SS, Manning AM and Anderson DW. SP600125, an anthrapyrazolone inhibitor of Jun N-terminal kinase. Proc Natl Acad Sci USA. 2001; 98:13681-13686.

13. Heo YS, Kim SK, Seo CI, Kim YK, Sung BJ, Lee HS, Lee JI, Park SY, Kim JH, Hwang KY, Hyun YL, Jeon YH, Ro $\mathrm{S}$, Cho JM, Lee TG and Yang CH. Structural basis for the selective inhibition of JNK1 by the scaffolding protein JIP1 and SP600125. EMBO J. 2004; 23:2185-2195.

14. Du L, Lyle CS, Obey TB, Gaarde WA, Muir JA, Bennett $\mathrm{BL}$ and Chambers TC. Inhibition of cell proliferation and cell cycle progression by specific inhibition of basal JNK activity: evidence that mitotic Bcl-2 phosphorylation is JNK-independent. J Biol Chem. 2004; 279:11957-11966.

15. Gao Y, Signore AP, Yin W, Cao G, Yin XM, Sun F, Luo Y, Graham SH and Chen J. Neuroprotection against focal ischemic brain injury by inhibition of c-Jun N-terminal kinase and attenuation of the mitochondrial apoptosissignaling pathway. J Cereb Blood Flow Metab. 2005; 25:694-712.

16. Daginakatte GC, Gianino SM, Zhao NW, Parsadanian AS and Gutmann DH. Increased c-Jun-NH2-kinase signaling in neurofibromatosis-1 heterozygous microglia drives microglia activation and promotes optic glioma proliferation. Cancer Res. 2008; 68:10358-10366.

17. Rahman M, Zhang Z, Mody AA, Su DM and Das HK. Intraperitoneal injection of JNK-specific inhibitor SP600125 inhibits the expression of presenilin-1 and Notch signaling in mouse brain without induction of apoptosis. Brain Res. 2012; 1448:117-128.

18. Okada M, Shibuya K, Sato A, Seino S, Watanabe E, Suzuki S, Seino M and Kitanaka C. Specific role of JNK in the maintenance of the tumor-initiating capacity of A549 human non-small cell lung cancer cells. Oncol Rep. 2013; 30:1957-1964.

19. Baserga R, Peruzzi F and Reiss K. The IGF-1 receptor in cancer biology. Int J Cancer. 2003; 107:873-877.

20. Allen GW, Saba C, Armstrong EA, Huang SM, Benavente S, Ludwig DL, Hicklin DJ and Harari PM. Insulin-like growth factor-I receptor signaling blockade combined with radiation. Cancer Res. 2007; 67:1155-1162.

21. Turner BC, Haffty BG, Narayanan L, Yuan J, Havre PA, Gumbs AA, Kaplan L, Burgaud JL, Carter D, Baserga $\mathrm{R}$ and Glazer PM. Insulin-like growth factor-I receptor overexpression mediates cellular radioresistance and local breast cancer recurrence after lumpectomy and radiation. Cancer Res. 1997; 57:3079-3083.

22. Mitra SK and Schlaepfer DD. Integrin-regulated FAK-Src signaling in normal and cancer cells. Curr Opin Cell Biol. 2006; 18:516-523.

23. Slack-Davis JK, Hershey ED, Theodorescu D, Frierson HF and Parsons JT. Differential requirement for focal adhesion kinase signaling in cancer progression in the transgenic adenocarcinoma of mouse prostate model. Mol Cancer
Ther. 2009; 8:2470-2477.

24. Eke I and Cordes N. Focal adhesion signaling and therapy resistance in cancer. Semin Cancer Biol. 2015; 31:65-75.

25. Sayeed A, Fedele C, Trerotola M, Ganguly KK and Languino LR. IGF-IR promotes prostate cancer growth by stabilizing $\alpha 5 \beta 1$ integrin protein levels. PLoS One. 2013; 8:e76513.

26. An J, Chervin AS, Nie A, Ducoff HS and Huang Z. Overcoming the radioresistance of prostate cancer cells with a novel Bcl-2 inhibitor. Oncogene. 2007; 26:652-661.

27. Su ZZ, Lebedeva IV, Sarkar D, Emdad L, Gupta P, Kitada $\mathrm{S}$, Dent $\mathrm{P}$, Reed JC and Fisher PB. Ionizing radiation enhances therapeutic activity of mda-7/IL-24: overcoming radiation- and mda-7/IL-24-resistance in prostate cancer cells overexpressing the antiapoptotic proteins bcl-xL or bcl-2. Oncogene. 2006; 25:2339-2348.

28. Di Pietro R, Centurione L, Sabatini N, Bosco D, Sancilio S, Garaci F, Rana R and Cataldi A. Caspase-3 is dually regulated by apoptogenic factors mitochondrial release and by SAPK/JNK metabolic pathway in leukemic cells exposed to etoposide-ionizing radiation combined treatment. Int J Immunopathol Pharmacol. 2004; 17:181190.

29. Mandal M, Olson DJ, Sharma T, Vadlamudi RK and Kumar R. Butyric acid induces apoptosis by up-regulating Bax expression via stimulation of the c-Jun N-terminal kinase/ activation protein-1 pathway in human colon cancer cells. Gastroenterology. 2001; 120:71-78.

30. Ehrlicher AJ, Nakamura F, Hartwig JH, Weitz DA and Stossel TP. Mechanical strain in actin networks regulates FilGAP and integrin binding to filamin A. Nature. 2011; 478:260-263.

31. Nakagawa $K$, Sugahara $M$, Yamasaki T, Kajiho $H$, Takahashi S, Hirayama J, Minami Y, Ohta Y, Watanabe T, Hata Y, Katada T and Nishina H. Filamin associates with stress signalling kinases MKK7 and MKK4 and regulates JNK activation. Biochem J. 2010; 427:237-245.

32. Calalb MB, Polte TR and Hanks SK. Tyrosine phosphorylation of focal adhesion kinase at sites in the catalytic domain regulates kinase activity: a role for Src family kinases. Mol Cell Biol. 1995; 15:954-963.

33. Rovin JD, Frierson HF, Jr., Ledinh W, Parsons JT and Adams RB. Expression of focal adhesion kinase in normal and pathologic human prostate tissues. Prostate. 2002; 53:124-132.

34. Cagnet S, Faraldo MM, Kreft M, Sonnenberg A, Raymond $\mathrm{K}$ and Glukhova MA. Signaling events mediated by $\alpha 3 \beta 1$ integrin are essential for mammary tumorigenesis. Oncogene. 2014; 33:4286-4295.

35. Steglich A, Vehlow A, Eke I and Cordes N. $\alpha$ integrin targeting for radiosensitization of three-dimensionally grown human head and neck squamous cell carcinoma cells. Cancer Lett. 2015; 357:542-548.

36. Serrels A, Lund T, Serrels B, Byron A, McPherson RC, von 
Kriegsheim A, Gomez-Cuadrado L, Canel M, Muir M, Ring JE, Maniati E, Sims AH, Pachter JA, Brunton VG, Gilbert $\mathrm{N}$, Anderton SM, et al. Nuclear FAK controls chemokine transcription, Tregs, and evasion of anti-tumor immunity. Cell. 2015; 163:160-173.

37. Tavora B, Reynolds LE, Batista S, Demircioglu F, Fernandez I, Lechertier T, Lees DM, Wong PP, Alexopoulou A, Elia G, Clear A, Ledoux A, Hunter J, Perkins N, Gribben JG and Hodivala-Dilke KM. Endothelial-cell FAK targeting sensitizes tumours to DNAdamaging therapy. Nature. 2014; 514:112-116.

38. McGrail DJ, Khambhati NN, Qi MX, Patel KS, Ravikumar $\mathrm{N}$, Brandenburg CP and Dawson MR. Alterations in ovarian cancer cell adhesion drive taxol resistance by increasing microtubule dynamics in a FAK-dependent manner. Sci Rep. 2015; 5:10.1038/srep09529.

39. Hirata E, Girotti MR, Viros A, Hooper S, Spencer-Dene B, Matsuda M, Larkin J, Marais R and Sahai E. Intravital imaging reveals how BRAF inhibition generates drugtolerant microenvironments with high integrin beta1/FAK signaling. Cancer Cell. 2015; 27:574-588.

40. Kreisberg JI, Malik SN, Prihoda TJ, Bedolla RG, Troyer DA, Kreisberg S and Ghosh PM. Phosphorylation of Akt (Ser473) is an excellent predictor of poor clinical outcome in prostate cancer. Cancer Res. 2004; 64:5232-5236.
41. Toren P and Zoubeidi A. Targeting the PI3K/Akt pathway in prostate cancer: challenges and opportunities (review). Int J Oncol. 2014; 45:1793-1801.

42. Fornaro M, Tallini G, Zheng DQ, Flanagan WM, Manzotti $\mathrm{M}$ and Languino LR. p27(kip1) acts as a downstream effector of and is coexpressed with the $\beta 1 \mathrm{C}$ integrin in prostatic adenocarcinoma. J Clin Invest. 1999; 103:321329.

43. Trerotola M, Ganguly KK, Fazli L, Fedele C, Lu H, Dutta A, Liu Q, De Angelis T, Riddell LW, Riobo NA, Gleave ME, Zoubeidi A, Pestell RG, Altieri DC and Languino LR. Trop-2 is up-regulated in invasive prostate cancer and displaces FAK from focal contacts. Oncotarget. 2015; 6:14318-14328. doi: 10.18632/oncotarget.3960.

44. Goel HL, Breen M, Zhang J, Das I, Aznavoorian-Cheshire S, Greenberg NM, Elgavish A and Languino LR. $\beta 1 \mathrm{~A}$ integrin expression is required for type 1 insulin-like growth factor receptor mitogenic and transforming activities and localization to focal contacts. Cancer Res. 2005; 65:66926700 